\title{
DA POSSIBILIDADE JURÍDICA DO PEDIDO NO PROCESSO DE CONHECIMENTO *
}

Denise Maria Weiss de Paula Machado 1

SUMÁRIO: Introdução - 1. A possibilidade juridica do pedido no processo civil brasileiro 2. Possibilidade juridica do pedido e mérito - 3. Extinção do processo por impossibilidade juridica do pedido e coisa julgada - 4. Possibilidade juridica do pedido e efetividade do acesso a justiça: 4.1. Direito, cultura e ideologia - 5. Conclusões - 6. Bibliografia

RESUMO: O trabalho pretende levar a efeito uma reflexão critica sobre a possibilidade juridica como condição da ação, buscando demonstrar que, embora seja o julgamento de carência de ação, por impossibilidade juridica do pedido, definido pelo legislador como sentença meramente extintiva, ou seja, que não alcança o mérito do processo, na verdade, a decisão que se tem, na maioria dos casos, é de mérito, porquanto respeita à pretensão levada ao conhecimento do juiz. Pretende-se demonstrar, assim, a incoerência entre a exigência dessa condição e a oricntação atual da processualistica e aportar, por fim à conclusão de que a possibilidade juridica do pedido, como condição da ação, haveria de ser excluída de nossa legislação processual.

PALAVRAS-CHAVE: Impossibilidade jurídica do pedido - Possibilidade jurídica do pedido - Carência de ação - Condições da ação

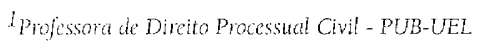

*Artigo exiratio da Dissertaço de Mestrado apresentado no $2^{\circ}$ semestre/1997 


\begin{abstract}
This paper iniends to make a critical reflection about the demand's legal possibility as a condition of the demand's right, aiming to prove that, although the action's lack judgement, based on demand's legal impossibility, is defined by the legislator as a simply ending sentence, which wouldn't reach the demand's object, in fact, the decision, in most cases, is definitive, cause decides about the aspiration taken to the judge's knowledge. It's intented to demonstrate, thus, the incoherence betwen this condition's exigence and the processualistic's actual orientation, pointing to the conclusion that the demand's legal possibility, as a condition of the action's right, should be excluded of our processual legislation.
\end{abstract}

\title{
INTRODUC ÃO
}

O Direito é um conjunto de normas e princípios regulamentadores das ativiclades do homem, eis que versa, em regra, sobre o comportamento nas relações interpessoais e sobre a esfera de liberdade dos cidadãos. Quando o agir de alguém interfere na eslera de direitos de outro, e não se resolve o conflito de interesses de forma natural, entra em cena o poder jurisdicional para a pacilicação com base no ordenamento jurídico, que, em última análise, apresenta-se como síntese aglutinadora dos valores socialmente dominantes. ${ }^{2}$ E pacífico, nesta ordem de idéias, que a função jurisdicional existe para solucionar a "patologia" das relações sociais, quando estas não se desenvolverem normalmente, com observância aos moldes e valores estabelecidos como justos pela própria sociedade.

A lunção jurisdicional é, pois, fundamental para a convivência harmônica cla sociedade institucionalizada, na medida em que realiza a paz

\footnotetext{
${ }^{2} \mathrm{Cl}$. WII.HII]M SAIFR, AIfgemeine Prozeßrechtslehre, apud ARRUDA ALVIM, Tratado de direito processual civil, p. 6.
} 
social através da atividade de aplicação do Direito. Desta atividade decorreno, também a certeza e a segurança do atendimento aos valores contidos nas normas, além da fixação de seu verdadeiro conteúdo e amplitude, Asșim, a importância do direito de ação está diretamente jungida a própria linalidade da jurisdição, uma vez que o exercício desse direito é yue dá o impulso necessário à realização da função estatal. Os dois institutos - a ação c a jurisclição - estão intrinsecamente ligados e constituem a base, ao lado da delesa e do processo, de todo o mecanismo de realização do Dircito, ou seja, de sua vivificação quando surgirem conflitos de interesses na sociedade.

O clireito de ação, enquanto garantia constitucional, apresenta-se como um direito inafastável e incondicionado, consubstanciado no que parte la cloulrina convencionou denominar como direito à administração da justiça, ou dircito de acesso à jurisdição. ${ }^{3}$ Como tal, o direito de ação reveste-se de natureza púhlica subjetiva, independendo sua existência de qualquer vinculacio ao direito material. Esse direito autoriza a iniciativa da instauraça da relação jurídica processual e, assim posto, corresponde ao que, neste trabalho, denominamos de "chave de ignição" do aparelho juciciano.

Entretanto, para que seja possivel ao cidadão obter uma sentença de mérito que atenda à finalidade precipua de eliminar o conflito de interesses, c necessínio que ele atenda a determinados requisitos, sem os quais não será possivel alcançr-se a decisão quanto ao que foi postulado. Assim, o direito de aço, embora entendido como autonomo e abstrato, para alcançar seu escopo hinal, está vinculado aos degraus metodológicos dos pressupostos procossuais, condiçóes da ação e mérito. Vale dizer que, tratando-se de processo de conhecimento, para que se atinja o objeto da demanda e se climine o conflito de interesses, devem ser apreciados certos aspectos relativos a exercício do direito de ação, que, juntamente com o próprio

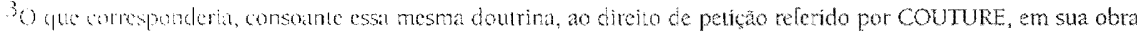
liundamentos do dircito processual civil, ediçăo brasileira, p. $45 \mathrm{ess}$.
} 
mérito, constituem o denominado trinômio de questões a ser conhecido pelo juiz $z^{4}$.

Essas questões prévias incluem, via de regra, a verificação dos pressupostos processuais e das condições da açãos. Portanto, do ponto de vista metodológico, o juiz deve verificar se a relação jurídica processual se estabeleceu e desenvolveu regularmente - ou seja, se estão presentes os pressupostos processuais -, e também se concorrem as condições da ação, que se consubstanciam nos requisitos para que tenha o particular o poder de exigir tais provimentos e que consistem em: possibilidade jurídica do pedido, interesse de agir e legitimidade para agir ${ }^{6}$.

\section{1 - A POSSIBILIDADE JURÍDICA DO PEDIDO NO PROCESSO CIVIL BRASILEIRO}

\section{Introduzida na ciência processual como condição da ação por} LIEBMAN, a partir de sua conferência realizada na Universidade de Turim, foi a possibilidade jurídica do pedido definida como 'l'ammissibilittá in

\footnotetext{
${ }^{4}$ Imporni suliente que säo questoes a serem enfrentadas e dirimidas pelo julgador, codas as controversins que surjam no desemolvimeno da relayio jundica processtal. Tais questoes poderao ter cunho meramene forma? -pressupostos processuais - on podera relacionat-se diretamente com a situaça latica trazida à aprectação do

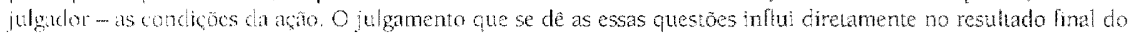
processo, una vez que pode ensciat a extinça do processo sem julgamento do merito, ou seja, sem decisão quanto a seu abjecto, consoante regram as disposiçoes da nossa legislaçäo processtal civil. Interessante observar, ainda, a visto de ETO FAZALART, para quem se constituem no objeto do processo todas as questoes, enquanto pontos duvidosos, que o juiz deva conhecer, sejam elas relativas ao rito ou ao merto. Sustenta o autor que: "il proceso ha,

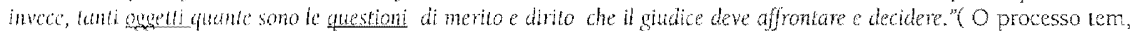
io contritio, tantos objclos quanto sejan as questoes - de merito e de direito - que o juiz deve entrentar e decidir). in Lezione di dirito processuale civile, p. 40.
}

5 C. DINAMARCO. Execuçắo civil, n. 19, p. 137. Face à posiçâo assumida pelo legislador, essas condiçôes ressilum de grande importhuin potgtanto implicam diretamente na afirmaçao do direito de açäo. Aliás. LIEBMAN

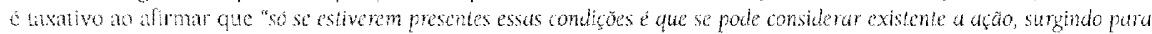

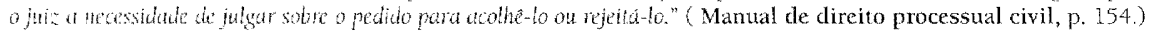
Se fatur uma deks, nâ se tem o diretio a sentença de mérito, ou seja, näo se tem o direito público subjetivo de obier to pocter jtrisdicional a decisăo sobre a situaça de conflito existente.

6 DONADO ARMIIIN, $\mathrm{cm}$ sua rotivel dba Legitimidade no direito processual civil, anota que não sâo apenas

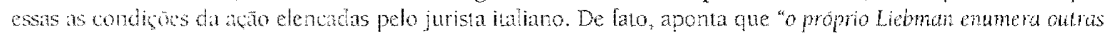

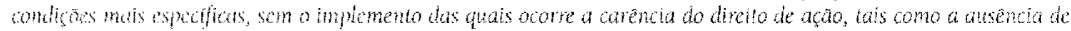

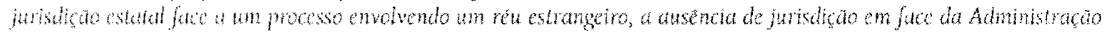

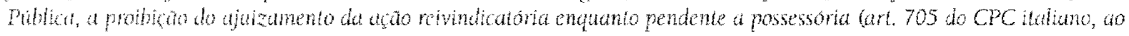
qual corresponte ant 923 do vigene CPC brasteiro e outres." A partir da análise de outras condiçoes da aça aponadas per BOTELHO DE MESQUTA em sua monografia Da ação civil, condui existiem "condigós da uğăo 
astratto del provedimento chiesto, secondo te norme vigenti nell'ordine giuridico nazionale", o que importa, dentro da ordem jurídica, no cabimento, em tese, da espécie cle decisão postulada pelo autor.

Embora tenha o ilustre processualista italiano, a partir da terceira edição de seu "Manual de Direito Processual Civil", excluído a possibilidade juridica do pedido do rol das chamadas condições da ação ${ }^{8}$ no mesmo ano em que foi lançada a ediçào referida, veio a lume o Código de Processo Civil hoje vigente, cujo anteprojeto de autoria de ALFREDO BUZAID adotou o trinômio de questões, consagrando, assim, a teoria até então abraçada pelo professor italiano. Destarte, embora tenha o idealizador da referida exigência dela abdicado, no processo civil brasileiro a possibilidade jurídica inclui-se no elenco das condições a serem preenchidas para o efetivo e pleno exercício do direito de ação.

Com arrimo nas lições de LIEBMAN, predominou por alguns anos o entendimento de que o exame da possibilidade jurídica deveria ser feito sob o ângulo da adequação do pedido ao direito material a que eventualmente colrespondesse a pretensão do autor, restando certa controvérsia na doutrina acerca do alcance dessa premissa. CANDIDO DINAMARCO ampliou esse pensamento, conceituando a possibilidade jurídica em termos negativos, afirmando que "há impossibilidade juridica quando o Estado, sem levar em conta as caracteristicas peculiares da situaçäo juridica concreta, nega aprioristicamente o poder de aça ao particular", seja tendo em vista a natureza do petitum, da causa petendi, ou seja em consideração às prerrogativas de uma das partes?.

\footnotetext{
7 A adnissibifiate em abstato do provimeno requerido, conforme as nomas vigentes no ordenamento jurdico nacinal. IEIMAN, Problemi, n. 6, p. 46. Assim, pam LIEBMAN, a verilicacto da possibilidale jurídica exige por parte du juiz un exme condictonal sobre a hipotese versada na situaço concren trazida a juzo. Ou seja, sobre a situacito de combito que the é apresentada, e preciso questionatr se, na circunst,ncia de sefem yerdadeiros os fatos narrados, cxiste bi cue ampare a pretensáo. En caso positwo, estata preenchido o requisito da possibilidade Juridia do pedido.

A. Con efeilo, os demais exemplos que anleriomente eram aponlados por LIEBMAN como hipoleses de impossbilidade jurdha do pedido, passatam a integrar o campo do interesse de agil, sendo sua a abmacão de que

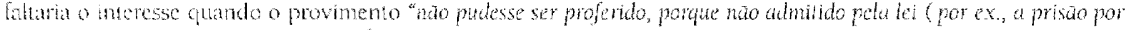
divids)". Na traducõo da obra por CANDIDO RANGEL DINAMARCO, há nola de esclarccinento de que a exc usão

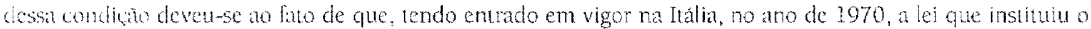

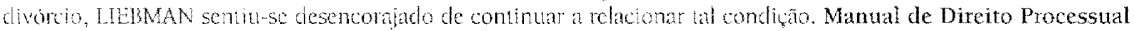
Civil, v. 1. p. 160-161, nata 106.

9 ixecucăo civil, 11,249 e 252.
} 
A concepção assim delineada é a adotada pela maioria da doutrina pátrialo, existindo, porém, processualistas de quilate que criticam a teoria eclotica de LIEBMAN, argumentando que, em verdade, o professor italiano propoe uma sintese na tentativa de conciliar as outras duas principais correntes acerca do direito de ação: a concreta e a abstrata.

De lato, contundente e criteriosa crítica às condiçöes da açäo é leita por CALMON DE PASSOS, especialmente em sua obra "A Ação no Direito Proccssual Civil" e em artigo intitulado "Em tôrno das condições da ação - a possibilidade jurídica do pedido"1. Sustenta o ilustre prolessor, que LIEBMAN não explica qual a natureza da atividade jurisdicional que se desenvolve quando a decisão do julgador é pela carência de ação12.

Entrctanto, é importante anotar desde logo, que para parte dos adeptos do trinomio, as condições da ação se justificam respaldadas na denominada tcoria da asserção, que propugna sua consideração ou avaliação "in staus assertionis", ou seja, de acordo com as afirmativas feitas pelo autor na petição inicial.

Para csses processualistas, para que seja possivel admitir a existência das chamaklas condições da ação adotadas pela legislação processual brasileira, deve-se entendê-las à luz da denominada teoria da asserção ou prospetuzzionc. Conforme essa teoria, as condições da ação são aferidas tão somente pelas alimaçōes feitas pelo autor na inicial, através das quais o julgador vai verilicar, sem qualquer análise vinculada ao mérito, se o autor reúne as condiçoes para receber julgamento de mérito.

Nesse sentido é a posição de KAZUO WATANABE13, LUIZ

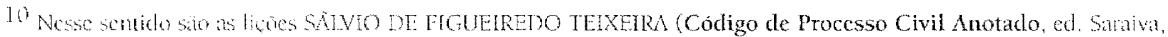
6a, a., p. 192), DONALDO ARMLLIN (Legitinidade para agir no direito processtal civil brasifeiro, p. 51);

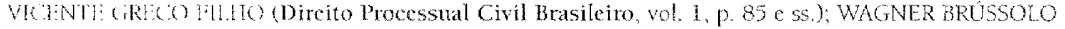

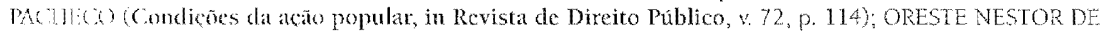
SOUA LASHO (A aço e stals condiçócs no processo civil de cognięa, in Processo civil: estudos em comemoracto aus 20 anos de vigéncia do Código de Processo Civil, Saraiva, 1995, p. 200-202); NELSON NERY

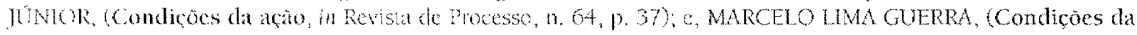
acau e merito no processo cautclar, in Revisu de Processo, n. 78, p. 196 197).

11 in Revisiz de nircilo Trocessmal owil

12 in Revista de nucio brocessin civit, wol. 4, p. 57-66.

13 Da cognicio no processo civil, p. 58.
} 


\section{GUILHERME MARINONI'14 e FLÁVIO LUIZ YARSHELL'15, entre outros.}

Contudo, sem questionar o mérito das lições desses autores, não parece que a tcolia da asserção resolva a problemática que envolve a possibilidade jurídica do pediclo, conforme se verá adiante.

No que se refere à ausência da possibilidade jurídica do pedido como condição da ação, estabelecem o artigo 267, "caput" e seu inciso Vl, do CPC, que extingue-se o processo, sem julgamento de mérito, quando não concorrer qualquer das condiçōes da ação. Por força dessa disposição legal, tem-se que o processo, como instrumento voltado à solução dos conflitos, e por consequência, à realização da jurisdição' ${ }^{16}$, será extinto sem alcançar seu objetivo precípuo, ou seja, sem que se obtenha uma decisão de mérito, quando näo existir no ordenamento previsão para a tutela jurisdicional requerida.

Pertencendo essa condição ao campo das questões que antecedem ao julgamento de mérito, ou seja, ao que se denomina de questōes prévias à decisão do mérito, a decisão por carência de ação, no caso de sua ausência, não se insere no provimento final que é suscetivel de adquirir a autoridade da coisa julgadar ${ }^{17}$.

Importa ainda destacar que, relativamente à verificaçăo de ausência das condicões, consoante as regras da legislação processual civil, não se opera a preclusãols, restando viável sua decretação em qualquer

\footnotetext{
L4 Novas linhas do processo civil, p. 120.

15 Tutcla jurisdicional especifica nas obrigacóos de declaração de vontade, p. 113.

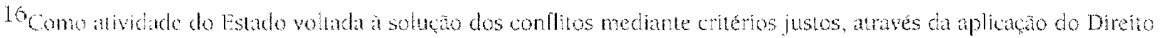

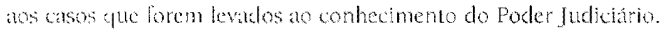

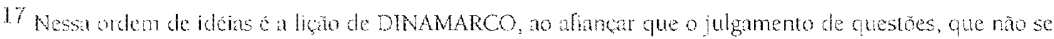
consthum no merho, ntegfa täo somente o "iter lógito" de conhecimento do juiz, do silogismo que é por de

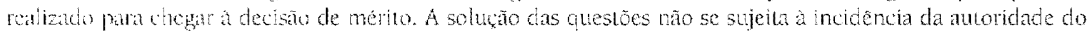

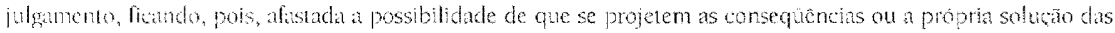

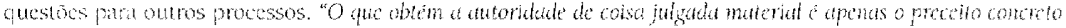

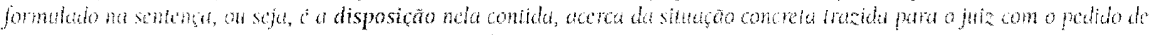
soittcio. (ir Fundamentos, p. 192. grifo do autor)

38 Segundo liçio de OVIDIO BATSTA DA SILVA, em seu Curso de direito processual civil, vol. 1, p. 172, preclusäo

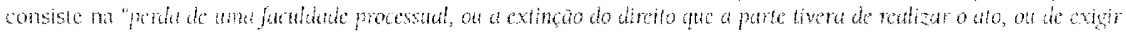

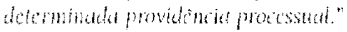


oportunidade processual, incluindo-se, evidentemente, a fase recursal ${ }^{19}$. mais relevante, nesse aspecto, é a possibilidade de repetição do feito, tendo em vista que a ocorrência da coisa julgada meramente formal não impede a renovação da ação, e, por consequência, a procrastinação do conflito.

A ausência da possibilidade jurídica do pedido, portanto, implica em três aspectos fundamentais: a) na decretaçăo de carência de ação, com impedimento do julgamento de mérito, e, portanto, do pleno cumprimento da função jurisdicional do Estado; b) a ausência da segurança e da certeza proporcionada pela coisa julgada material decorrente das decisóes de mérito; $e$, por fim, c) a manutenção do estado de insatisfação e insegurança em face da possibiliclade de rediscussäo judicial da matéria.

\section{2 - POSSIBILIDADE JURIDICA DO PEDIDO E MÉRITO}

Diz-se que ao verificar a impossibilidade jurídica do pedido, está o poder jurisdicional a proclamar, desde logo, a inviabilidade de atingir-se o provimento pretendido mediante apreciação dos fatos, porque estes, ainda que ocorridos, năo encontram enquadramento em qualquer previsão contida no sistema de direito substancial20.

Considerando-se que a impossibilidade jurídica do pedido é verificada tanto pelo aspecto negativo - inexistência de previsão em abstrato -, quanto pelo aspecto positivo - existência de expressa vedação legal a determinado tipo de pretensão -, é necessário perscrutar a atividade jurisdicional que se desenvolve em uma e outra circunstância, bem como o resultado que se obtem em carla qual.

Na maioria das situaçoes levadas ao conhecimento do juiz através das demandas, não há como se fazer juizo hipotético quanto à existência de direito aplicável a determinada situação fática. Isto porque, se a vedação não

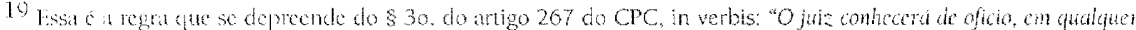

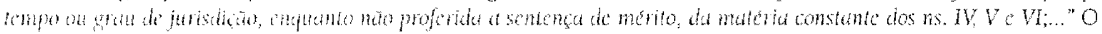

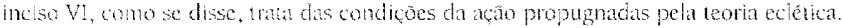

20 CANDIOO IINAMARCO Excoucato civil, p. 3843855
} 
é verilicável de pronto, será necessária a análise dos fatos e da pretensão do autor, e a conclusão que se chegue quanto a estes será relativa ao próprio objeto do processo, e, nessa ordem, será julgamento de mérito. Desse modo, uma análise hipotética sobre o pedido, a pretensão, quando esta não for manilestamente vedada, dificilmente deixará de alcançar o próprio mérito da causa $^{21}$.

Dizer-se, assim, que essa análise deve ser feita em sentido hipotético, soa como ignorar o que a prática exige que se realize. Em outras palavras, não há juízo hipotético sobre possibilidade jurídica. Ou o pedido é atendido, ou não o é. Se o ordenamento não agasalha a pretensão contida no pedido do autor, ele não tem esse direito. E isso, efetivamente, importa em decisão sobre o objeto do processo, ou sobre o mérito, conforme linguagem adotada pelo legislador:

Nas situações onde a vedação legal é expressa, o ordenamento jurídico obsta a Lutela exatamente porque interesses de determinada natureza estão desguarneciclos da proteção decorrente do direito material, a sustentar a pretensão. Se como ensina CARNELUTTI, "las normas materiales componem inmediatamente un conflicto de intereses, imponiendo una obligación y atribuyendo - evenualmente - - un derecho (subjetivo); las normas instrumentales, lo componen mediatamente, atribuyendo un poder (de componerlo) e imponiendo correlativamente una sujeción"22, o que inexiste, nos casos referidos, é o próprio clireito material a fundamentar a composição do suposto conflito de interesses.

Vale dizer, verificando-se aprioristicamente existir na lei o impedimento da defesa de determinados interesses, ou verificando-se, após a instrução do feito a análise de todas as questóes de fato e direito que cercam a pretensão, que não há direito a possibilitar a concessão da

\footnotetext{
21 A rita kwak a deito por CALMON DE PASSOS, no arigo Em torno das condiçoses da aço 6 a possibilidade juriba do pedido, aplica-se, de forma conundente, a teora da assercäo. Dentre virios exemplos, figura siluaces

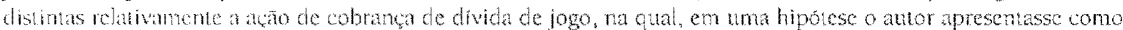

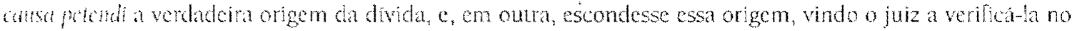

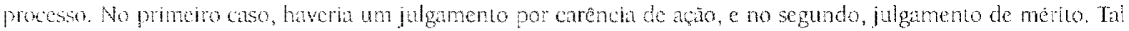

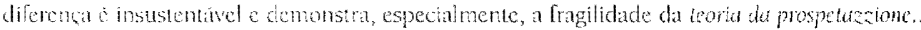

22 Sistema de derecho procesal civil, tomo 1, p. 57-58.
} 
providência estatal requerida, o que se tem é julgamento de mérito, e não simples julgamento por carência, anterior ou preliminar à análise do mérito. O que resulta, nessa hipótese, é uma decisão que, em verdade, revela não ter o autor o direito que pretendia fosse tutelado, porquanto seu interesse não é juridicamente protegido, e isso é decidir-se sobre o objeto da ação, é decisäo acerca da lide - como o conflito de interesses trazido ao conhecimento do juiz - e da pretensão a ela referente, e portanto, decisão de mérito. Haverá, então, que ter esse julgado a força decorrente da imulabilidade de seus efeitos, sob pena de violação de preceitos básicos da atividade jurisdicional. Tal violação verifica-se, especialmente, no que respeita ao desenvolvimento de atividade jurisdicional inútil, tendo em vista a possibilidade de repetição do feito.

Em verdade, se considerarmos a classificação dos interesses em primarios e secundarios ${ }^{23}$, e se considerarmos que o ordenamento jurídico deline quais são os interesses juridicamente protegidos ou merecedores de tutela, caso o autor formule pretensão que não enseja proteção pelo direito material, o caso será de improcedência. Os meros interesses, na lição de ARRUDA ALVIM24, consistem naqueles que não podem lograr a tutela jurisdicional, o que, em termos concretos, representa a situação açambarcada pela inclicação legal de pedido juridicamente impossível. Tal circunstância, Lodavia, é ratada pela legislação processual brasileira como hipótese de extinção do processo sem julgamento de mérito, por carência de ação em razão da impossibilidade jurídica do pedido.

Em uma linguagem bastante informal poderíamos afirmar que, se o caso apresentado não for digno de proteção jurisdicional porque se trata de situação sequer prevista no ordenamento em razão de sua injuridicidade, deve ser a demanda julgada improcedente por inexistir direito subjetivo a ser amparaclo. Entretanto, se não houver previsão in abstrato para a situação levada ao conhecimento do juiz, mas verificar ele que se trata de interesse

\footnotetext{
23 Coblorme expo. ARKUDA AIVM em seu Tratado, o interesse primáro é aquele que liga o individuo a

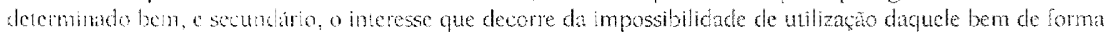

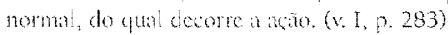

$2+0,0.11,0,283$
} 
jurídico, ou seja, que eletivamente existe um conflito que mereça a atenção e a atuaçio do poder jurisdicional na medida em que revela uma "patologia da relação social", deverá o juiz acolher o pedido, independentemente de previsão legal, fundado nos princípios orientadores da própria atividade jurischicional e tendo por norte a idéia de acesso à Justiça.

Não se pode negar a conexão da ação com o direito material. Sua ligação é instrumental, e a ação existe para fazer valer o direito material que, por uma situação concreta ou iminente não pode ser exercido plenamente. Entretanto, nem todos os interesses tuteláveis pelo direito, ou todas as situaçoes deles decorrentes, vêm expressamente previstas no ordenamento juridico, e o escopo da atividade processual não se limita exclusivamente à aplicação da lei25. Assim, se o julgador verificar que se trata de situação fática digna do proteção estatal, independentemente de expressa previsão legal, deverá exercer regularmente sua atividade, e não renunciar à função que the cabe com exclusividade, e da qual se tornou devedor a partir do regular exercício do direito de ação pelo jurisdicionado.

\section{3 - EXTINÇÃO DO PROCESSO POR IMPOSSIBILIDADE JURIDICA DO PEDIDO E COISA JULGADA}

Con onforme estabelece a legislação pátria, a ausência de qualquer das condicôes da ação importa em extinçăo do processo sem julgamento de mérito, e tal decisäo, a teor do que dispóe o artigo 268 do diploma processual civil, "não obsta a que o autor intente de novo a açäo". Sendo permitida a repropositura da demanda, é válido dizer que a sentença que julga o autor carecedor de ação por impossibilidade jurídica do pedido não agregra aos seus efeitos a qualidade de imutabilidade concernente à coisa julgada material, uma vez que não projeta seu resultado para fora dos limites do processo.

\footnotetext{
25 A aplicano a la consise no escopo jurdico da atividade jurisdicionate do processo, mas ao lacio deste,

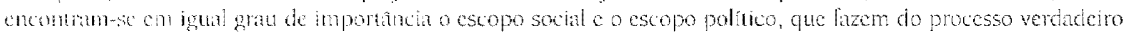
insturnento de acesso is orden juretion usta.
} 
Ao contrário, tal decisão alcança tão somente a irrecorribilidade emergente da coisa julgada formal, que, em verdade, equivale à ocorrência do fenômeno da preclusăo ${ }^{25}$, referindo-se, entretanto, a uma sentença meramente terminativa, ou seja, ao ato decisório que extingue o processo sem a análise da pretensão veiculada na demanda27.

Deste modo, pela orientação adotada pelo Código de Processo Civil, em ocorrendo julgamento por impossibilidade jurídica do pedido, não há como se cogitar da coisa julgada material, hábil a impedir a repetição do exercicio da atividade jurisdicional, uma vez que a extinção do processo sem julgamento de mérito não é protegida pela imutabilidade da res iudicata. Isso signilica, pois, autorizar a invocação repetida da prestação da tutela, em detrimento da orientação maior que permeia o processo civil moderno, com vistas aos seus escopos políticos, sociais, econômicos e jurídicos.

Neste aspecto, o pensamento de ARRUDA AIVIM é no sentido de quando as decisões, ainda que utilizado o termo carência de ação, definirem a ausência de direito, fique obstado novo acesso ao Judiciário. "Se assim näo se admilir" conclui o mestre, "chegar-se-ia ao despautério de ser possivel repetir-se indefinidamente o processo, com a mesma ação (o que é admitido pelo art. 268), ate se cncontrar um magistrado que decidisse diferentemente."28

DONALDO ARMELIN, acompanhando a idéia de ARRUDA ALVIM e de FREDERICO MARQUES29, leciona que sendo o julgamento por impossibilidade jurídica uma forma de improcedência prima facie, não há,

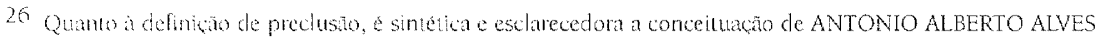

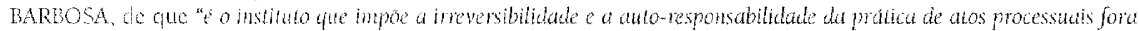

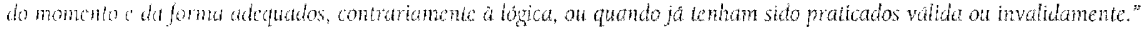
Da prcclusáo processual civì, 2a, cd., Sắo Paulo, RT, 1992, p. 222.

27 Necessitio ressaltar que a intença do legistador fol de que, verificando, o juiz, desde logo, a impossibildade jundica clo pedido, proferisse jugimemo contome o estado do processo, determinando sua extinça sem juganyento de merito. $15 s 0$, porem, exighir da parte do jugador uma noço clara e segura da possibidade furídica

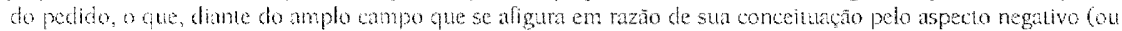
seja, dit inexistencia de expressa vedaça), se torna taréa bastane dificil. Lembre-se, lodavia, que o momento processual da prolaģo da sentenç é irrelevanc, nào havendo modifeaçao da natureza da matéria a ser decidida polo magistado C. BREVO MORERA MUSS1, As condiçóes da ação e a coisa julgada, in Revista de Processo n. $45,[2,44$,

28 Tratado de dircito processual civil, v., , p. 348, con grifos do autor.

29 Institucoses de direito processual civil, v. 5, p. 43. Nesse sentido, lamberm a posiça de BRENO MOREIRA MUSSI, no amgo intulado As condiçoes da ação e a coisa julgada, in Revista de Processo n. 45, p. 44 
ontologicamente, diferença entre esta decisão e aquela que julga improcedente o pedido por ausência de suporte fático para a subsunção à norma invocada. Os efeitos que emergem dessa constatação, a rigor, são os mesmos, e, nessa perspectiva, não há como deixar de atribuir a tal julgamento a Corça da coisa julgada material e a imutabilidade dela decorrente ${ }^{30}$.

Aliás, a projeção dos efeitos da decisão para fora dos lindes processuais é aspecto que serve à defesa da idéia de inocorrência da coisa julgada material, no julgamento por carência em razão de impossibilidade jurídica do pedido. Argumenta-se que, por não acarretar qualquer alteraçăo na situação jurídica substancial externa e anterior ao processo, a decisão não contém a qualidade da coisa julgada material, mas tão somente alcança a coisa julgada formal.

Para DINAMARCO, porém, a sentença que pronuncia a impossibilidade jurídica do pedido faz coisa julgada, na medida em que deline "uma situação que transcende a vida e as vicissitudes do processo que se extingue, alingindo uma situação juridica exterior e anterior a este (a ação)." Ressalva o mestre, que sua posição neste sentido é minoritária31.

O que importa destacar, neste passo, é que o julgamento por impossibilidade juridica do pedido, em sendo uma decisão de mérito, mereceria ser coberto pela força da imutabilidade decorrente da coisa julgada material. Essa imutabilidade, por evidente, não obstaria o acesso ao Judiciário nas situaçōes em que outra configuração jurídica fosse atribuída a certos interesses. Ficaria, assim, afastada a hipótese de impedimento da fruição de eventuais avanços. Como bem ressalva ARRUDA ALVIM, "é inerente à coisa julgada, o sentido e a função de subsistir a imutabilidade dela emergente, $e$, obstativa de novo acesso ao Judiciário, desde que e quando, igualmente, persistam as condições fáticas e juridicas coevas à sentença." 32

No mesmo sentido EGAS DIRCEU MONIZ DE ARAGÃO sustenta,

\footnotetext{
30 Legitimidade para agir no direito processual civil brasileiro, p. 53-54.

31 Execuço civil p. 388 , esp nota 94.

32 Manual de direito processual civil, 4.11, p. 163 (grifos do autor).
} 
fundado em SAVIGNY, que uma sentença "não pretende nem pode jamais decidir senão com respeito à época em que foi pronunciada. Todas as modificações que as relaçoes juridicas possam sofrer posteriormente estão fora de sua abrangència; não exerce ela, pois, influência alguma sobre a ação que tenha por objeto uma dessas modificações". Assevera ainda que os limites temporais afirmam a inextensão da coisa julgada a situações ou pretensões novas, que por terem surgido futuramente não podem a ela subordinar-se, seja por não integrarem a res iudicata, seja por consubstanciarem outra res. "Com efeito", afirma o processualista, "se fatos ulteriores geram outro pedido, ou outra causa de pedir, a pretensão que neles se ampare é distinta da que fora anteriormente julgada." 33 Não há, pois, que se falar em prejuízo advindo da coisa julgada material a ser atribuída aos julgamentos por carência de ação por impossibilidade jurídica do pedido.

O juízo de que tal decisão haveria de fazer coisa julgada material fundamenta-se em dois aspectos: o primeiro, de que o julgamento é de mérito, e, nessa perspectiva, deveria ser acobertado pela imutabilidade da res iudicata. A inserção de decisão dessa ordem em sede eminentemente processual - assim considerados as sentenças extintivas - é equivocada. $O$ segundo, relaciona-se com a ótica que se deve ter do processo, e de todos os institutos a ele referentes, uma vez que não há como aceitar que a ausência da força da res iudicata possa autorizar a movimentação repetida, inócua e onerosa da atividade jurisdicional. Isso vem em detrimento dos princípios que a orientam e do próprio objetivo final da jurisdição, que é a pacificação social mediante a solução definitiva dos conflitos de interesses.

\section{4 - POSSIBILIDADE JURÍDICA DO PEDIDO E EFETIVIDADE DO ACESSO À JUSTIÇA}

A luz que orienta a atividade jurisdicional atualmente vem no sentido de que, sempre que possível, deva o juiz auxiliar na consecução dos

33 Sentença e coisa julgadla, p. 199-200. 
objetivos da jurisclição, porquanto a neutralidade que deve ser inerente ao exercício da jurisdição diz respeito às partes, mas não à Justiça. O juiz, evidentemente, não pode assumir a posição de uma ou outra parte no processo ou dele participar como se fosse autor, réu ou terceiro interessado, mas deve, e isso sim, assumir a defesa da ordem jurídica na condição de condutor do processo como instrumento de realizaçäo do Direito.

Sendo essa a tendência atual, resta evidente uma indagação relativa ao tema do presente trabalho: por que năo pode o juiz alcançar julgamento de mérito em feito onde determinado pedido não corresponda à previsão legal, invocando os princípios que formam e informam o processo? Ao que parece, amparar-se o julgador em ausência de expressa previsão legal para sustentar sua negativa de jurisdição significa incidir em extrema incoerência com a linha orientadora da ciência processual moderna34.

Com eleito, a partir do momento em que o julgador declara o autor carecedor de ação, por ser o seu pedido juridicamente impossivel, está a negar a prestação da tutela jurisdicional que lhe compete, fundado em uma noma de direito substancial ou na sua ausência. Como já se frisou no item anterior, concretamente ocorrem situações onde, não obstante se julgue o autor carecedor de ação por impossibilidade jurídica do pedido, verifica-se verdadeiro julgamento de improcedência da pretensão deduzida em juízo. Mas, se ao contrário, a renúncia fundar-se em ausência de norma a autorizar a emissão do provimento, o que se tem é concreto boicote ao direito de ação com decorrente omissão do Estado no exercício de sua função jurisdicional.

Ocorre, porém, que o Estado não pode renunciar ao exercício da funçăo que the compete de prestar a tutela jurisdicional calcado em uma

\footnotetext{
34 Volando at licos do mestre DINAMARCo, cumpre destacar que ha, de sua parte, reconhecimento de que seria muito indeteminado direto de acto que sinplesmene garntisse o acesso ao Judichrio, sem asscgurar que desse

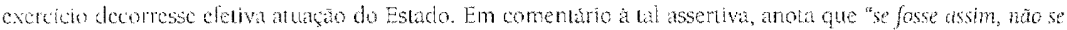

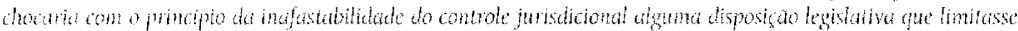

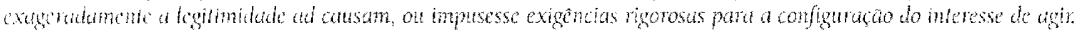

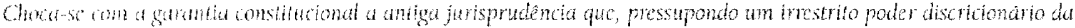

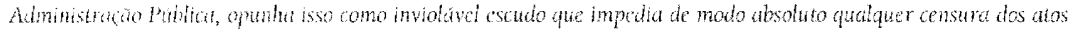

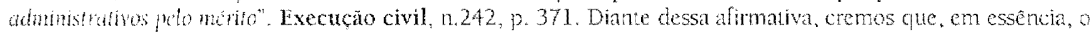
pensmento do autor seja no mesmo sentido do que ora se expoe. O exemplo aponado, alinat, consiste exalamento an una expressâto de impossibilidade jurdica do pedido a alastar a análise de mérito pelo Judiciaro cle delermanada sillaçăn.
} 
hipotética ausência de previsão para o provimento solicitado. Admitir-se tal situaçăo significa tornar tábula rasa a previsão constitucional de inafastabilidade do controle jurisdicional e todos os demais princípios que dela decorrem.

Fala-se em hipotética ausência de previsão porque, como se viu, a questão das condições da ação é sustentada sobre um juízo hipotético acerca da situação levada ao conhecimento do juiz. Ora, se tal juízo é hipotético porquanto, segundo os defensores do trinômio, ele se faz sem a análise efetiva da lide, mas com base em mero exame condicional sobre a hipótese versada na situação trazida a juízo -, como pode servir de escora para a renúncia ao cumprimento da função jurisdicional da qual o Estado é devedor na relação que mantém com as partes através do processo?

Reforça ainda esse argumento, o aspecto de que a própria lei substancial - mais precisamente o art. $4^{\circ}$ da Lei de Introdução ao Código Civil -, está a prever a possibilidade de fundamentar-se o julgador nos princípios gerais de direito, bem como na analogia e nos costumes, para prolerir julgamento nas hipóteses em que inexista previsão legal para a situação posta para a apreciação do Judiciário. Do mesmo modo, o artigo 126 do Código de Processo Civil estabelece que "o juiz não se exime de sentenciar ou despachar alegando lacuna ou obscuridade da lei", competindothe, ainda conforme o dispositivo, recorrer à analogia, aos costumes e aos princípios gerais de direito ${ }^{35}$.

A partir do que estabelecem esses dispositivos, é possivel afirmar que nosso sistema, admitindo a existência de lacunas, indica os mecanismos de preenchimento a serem utilizados pelo julgador, evitando, com isso, o exacerbamento do poder do magistrado e orientando sua atividade a partir dos parâmetros estabelecidos na própria lei.

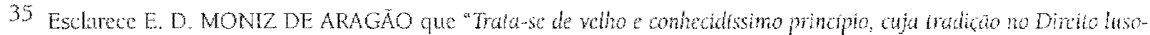

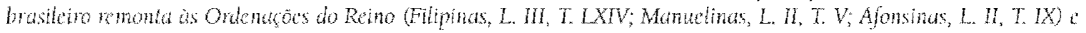

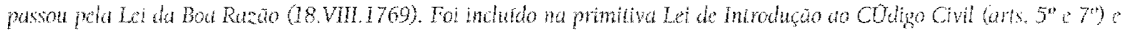

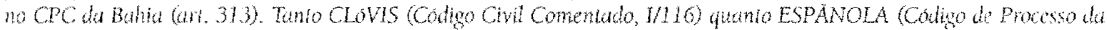

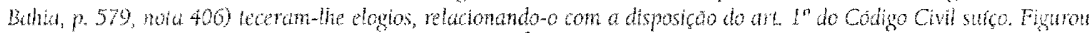

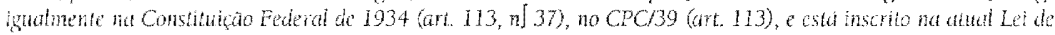
Introduço to Codigo Civi." (nota 108, p. 83, Sentença e cołsa julgada, La, ed., 1992).
} 
O processo, destarte, existe em função do próprio conflito de interesses que veicula. E a atividade jurisdicional, que se realiza a partir do exercício do direito de ação e que se plenifica mediante a concessão da tutela requericla em lace de pretensões justas e insatisfeitas, há que ser eficaz, a fim le cumprir com os objetivos que compóem sua própria razão de ser. Diante disso, é válido alirmar que o processo só será eficaz quando proporcionar concrela soluçăo ao conllito de interesses apresentado ao julgador, através da prolação de uma sentença de mérito, que produza os efeitos de segurança juridica decorrentes da coisa julgada material.

\section{1 - Direito, cultura e ideologia}

Em uma sociedade democrática, o processo há que servir como instrumento garantidor dos verdadeiros elementos culturais e axiológicos que a regem, afirmando princípios e regras de convívio dirigidas a um desenvolvimento harmonioso do grupo social. O Estado, por sua vez, tem por premissa consubstanciar esses elementos através da organização social. Nessa esteira, o Direito, como uma instituição do Estado, deve retratar os ideais e valores da sociedade no campo ético, político e ideológico.

Sobreleva, pois, de absoluta importância a concepção de processo como instrumento de pacificação social, e o entendimento que se dè à forma de sua eletivação ou realização. Destaca-se, portanto, o caráter de instrumentalidade da ação e de todo o processo, visto atualmente não só como meio garantidor da efetivação de direitos, mas como um instrumento voltaclo a resultados benélicos aos cidadãos.

Quanclo a lei, no artigo $2^{\circ}$ do CPC, dispõe que a tutela jurisdicional será prestada "nos casos e formas legais", está a referir-se não só à adequada formulação do pedido de proteçăo, mas também às situações previstas na lei substancial, enquanto interesses tuteláveis pelo Direito. Surge, então, uma primeira preocupação na atividade jurisdicional, que respeita a ausência de previsão para as situações que podem surgir em decorrência das relaçoes sociais a calla dia mais complexas.

Vale dizer; quando se afirma que o juiz deve aplicar o direito não se 
pode entender, tão somente, a aplicação da lei. A lei é ponto de partida, não de chegada. ${ }^{36}$ Atuando jurisdicionalmente, compete ao magistrado o poder-dever de completar a lei no momento de sua aplicação ao caso trazido ao seu conhecimento, fundamentando-se no ordenamento jurídico como um todo, que inclui não só a lei, mas também os princípios gerais e os costumes, e, principalmente, as diretrizes constitucionais.

O que se traduz na mantença da possibilidade jurídica como condição para o atingimento da decisão de mérito é o positivismo juridico exacerbado, a autorizar - senão a impor -, que o julgador se abstraia de qualquer atividacle valotativa e limite-se a reproduzir a suposta vontade da lei. Ou seja, ao deparar-se com uma demanda que exponha situação de fato não prevista pela norma, o juiz deverá prescindir de qualquer juízo de valor quanto ao fato em si.

O juiz, ao julgar o caso levado ao seu conhecimento, dizendo o direito, não pode olvidar que este é resultado da obra humana, é um objeto cultural que se compóe de valores. E nessa atividade ele estará buscando o verdadeiro sentido de realização da justiça mediante a aplicação do direito, que não se esgota na letra da lei, mas sim, que se refere a todo um processo de integraçio entre o lato, os valores predominantes no contexto social e as normas. O juiz, muito mais do que o legislador, está em contato direto com os sujeitos do conflito de interesses. É ele quem percebe com mais clareza a verdacleira amplitude do conflito, e é quem, com mais segurança, poderá avaliar a importância e a necessidade da atuaçäo jurisdicional ${ }^{3 \%}$.

E essa atuação deve estar em consonância com os verdadeiros escopos da jurisclição, que incluem, além da linalidade jurídica, objetivos políticos e sociais. A ordem jurídica justa não se limita às expressas normas de direito

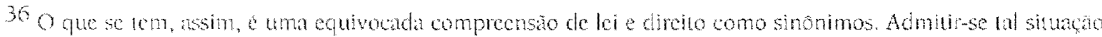
implica reduzir o verdabiro significado do direizo a kenicaldade da lei, restando ao magistrudo tio somente agir

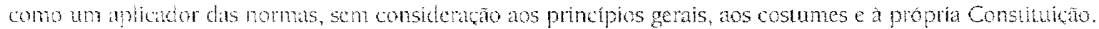

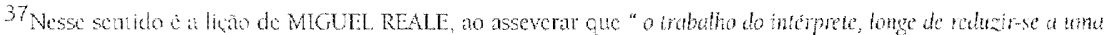

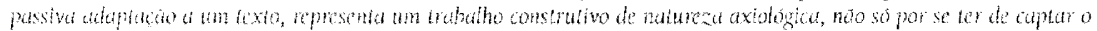

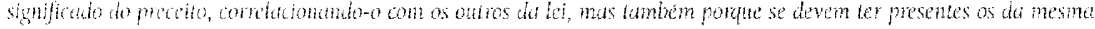

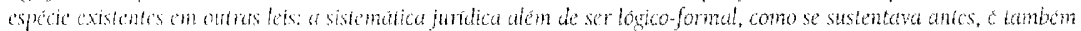
"xiolgyicu on valubriva." (Liçoes preliminares de direito, Ed Jose Bushatsky, 1974, p. 320).
} 
substancial. Ela se revela nos valores e nos ideais da própria sociedade, e deve ser compreendida como todo o conjunto de normas e princípios que a regem, estejam ou não expressamente previstos na legislação ordinária.

Por força disso, merece ser afastada da legislação processual a cxigencia de "possibilidade juridica do pedido" a obstar o pleno e efetivo exercicio do direito de ação. Competirá ao Judiciário, através do magistrado, decidir com base no ordenamento jurídico, e especialmente na Constituição, todos os casos de conflitos de interesses juridicamente relevantes, dandoThes solucaro que atenda aos valores da sociedade. Assim, e só assim, estará o Judiciário exercendo com inteireza seu verdadeiro papel, e servirá o processo como eletivo instrumento de realização de Justiça.

\section{CONCLUSÕES}

A impossibilidade jurídica do pedido decorre de duas ordens distintas de motivos: ou pelo fato de inexistir direito objetivo substancial a admitir, em tese, o pedido; ou por expressa proibição legal de manifestação judicial sobre a questão. Conclui-se, pois, que disposições legais de caráter ordinário - ou sua ausência - têm o condão de, por força de análise meramente hipotética, obstar o exercicio do direito de ação, e por consequência, a plena realização da funçăo jurisdicional.

$\mathrm{Na}$ maioria dos julgamentos por carência de ação em razão da impossibilidade jurídica do pedido, o que se tem, em termos práticos, é um julgamento do improcedência do pedido, e, pois, do mérito da questão, porquanto, ao declarar o pedido juridicamente impossível, o julgador está a negar a autor o pretenso direito alegado.

Tal julgamento, por força das disposições legais, năo é admitido como scndo de mérito e, portanto, não se reveste dos efeitos da coisa julgada material e não impede a propositura de nova ação. Tal situação, ao frustrar o escopo de proporcionar a eliminação do conflito mediante a tutela estatal, contraria a própria idéia de efetividade e eficácia dos provimentos jurisdicionais. 
Verifica-se, desse modo, no que respeita à exigência de possibilidade juríclica do pedido para a prolação de sentença de mérito, incoerência entre a linha que orienta a nova concepção cientílica voltada a um processo civil de resultados e a negativa de jurisdição calcada na ausência da previsão em abstrato de norma protetora do provimento solicitado.

$O$ direito objetivo não regula de forma exaustiva todos os interesses juridicamente tuteláveis, mas nosso sistema, admitindo a existência de lacunas, indica os mecanismos e estabelece os limites de integração a serem utilizados pelo julgador na tarela de efetivação da ordem jurídica. Haveria o magistrado, nesses casos, que orientar-se pelos próprios critérios estabelecidos na lei para julgar os casos que não se adequassem às expressas previsões legais.

Para que se tenha uma atividade jurisdicional coerente com a orientação propugnada pela nova processualística, conclui-se que, se o julgador verificar que se trata de situaçäo fática digna de proteção estatal, independentemente de expressa previsão legal, deverá exercer regularmente sua atividacle. Não pode, o magistrado, renunciar à função que lhe cabe com exclusividade, e da qual tornou-se devedor a partir do regular exercício do diretto de ação pelo jurisdicionado.

Verilicando aprioristicamente existir na lei o impedimento da defesa de determinados interesses, ou verificando, após a instrução do feito e a análise de lodas as questões de fato e direito que cercam a pretensão, que não há direito a possibilitar a concessão da providência estatal requerida, deve o julgamento ser de improcedencia do pedido do autor, o que consubstancia julgamento de mérito. Haverá, então, que ter esse julgado a força decorrente da imutabilidade de seus efeitos, sob pena de violação de preceitos básicos da atividacle jurisdicional.

Conclui-se, portanto, que a possibilidade jurídica não deve ser exigida como condição da ação a fim de que o processo possa alcançar sua real finalidade, competindo ao julgador analisar a pretensão do autor em conformidade com o sistema juridico vigente, que traz, em seu corpo, os valores da sociedade a que se refere. Isto porque, o exercício da jurisdição 
interessa principalmente ao próprio Estado, no que respeita à eliminação dos conflitos e à manutenção da ordem social. Tal atitude, além de consistir em benefício ao autor, atenderia aos objetivos do Estado e da função jurisdicional que the compete - cujo ponto de partida é a ação, e instrumento o processo - na busca da efetivação de uma ordem jurídica justa.

\section{BIBLIOGRAFIA}

ARMELIN, Donaldo. Legitimidade para agir no direito processual civil brasileiro. Säo Paulo, RT, 1979.

ARRUDA AIVIM NETTO, José Manuel de. Tratado de direito processual civil 2a. ed., Săo Paulo, Revista dos Tribunais, 1990 , v. 1

CAPELIETTI, Maro e GARTH Bryant. Acesso à justiça. trad. de Ellen Gracie Northfleet. Porto Alegre. Sérgio Fabris, 1988.

CARnelutT, Francesco. Sistema di Diritto Processuale Civile tomos I e III. Padova, Cedam, 1936. DINAMARCO, Candido Rangel. Fundamentos do processo civil moderno. la. ed. São Paulo, RT, 1985. FAZZALARI, Flio. Lezioni di diritto processuale civile tomo 1, Fadova, Cedam, 1985.

LIEBMAN, Enrico Tulio. Manual de direito processual civil. vol. 1, 2a. ed. Trad e notas de Candido Rangel Dinamarco, Rio do Janeiro, Forense, 1985.

MOREIRA, José Carlos Rarbosa. O novo processo civil brasileiro. vol. 1, 18a. ed. Rio de Janeiro, Forense, 1906.

PASSOS, Joaquim José Calmon de. Comentários ao Código de Processo Civil, vol. III arts. 270 a 331.

5a. ed. Rio de Janeiro, Forense, 1988.

SILVA, Ovidio A. Baptista da et al. Teoria geral do processo civil. Porto Alegre, Letras Jurídicas, 1983. WATANABE, Kazuo. Da cognição no processo civil. Säo Paulo, RT, 1987. 